\title{
A 3D particle Monte Carlo approach to studying nucleation
}

\author{
Köhn, Christoph; Bødker Enghoff, Martin ; Svensmark, Henrik
}

Published in:

Journal of Computational Physics

Link to article, DOI:

10.1016/j.jcp.2018.02.032

Publication date:

2018

Document Version

Publisher's PDF, also known as Version of record

Link back to DTU Orbit

Citation (APA):

Köhn, C., Bødker Enghoff, M., \& Svensmark, H. (2018). A 3D particle Monte Carlo approach to studying nucleation. Journal of Computational Physics, 363, 30-38. https://doi.org/10.1016/j.jcp.2018.02.032

\section{General rights}

Copyright and moral rights for the publications made accessible in the public portal are retained by the authors and/or other copyright owners and it is a condition of accessing publications that users recognise and abide by the legal requirements associated with these rights.

- Users may download and print one copy of any publication from the public portal for the purpose of private study or research.

- You may not further distribute the material or use it for any profit-making activity or commercial gain

- You may freely distribute the URL identifying the publication in the public portal

If you believe that this document breaches copyright please contact us providing details, and we will remove access to the work immediately and investigate your claim. 


\title{
A 3D particle Monte Carlo approach to studying nucleation
}

\author{
Christoph Köhn*, Martin Bødker Enghoff, Henrik Svensmark \\ Technical University of Denmark, National Space Institute (DTU Space), Elektrovej 328, 2800 Kgs Lyngby, Denmark
}

\section{A R T I C L E I N F O}

\section{Article history:}

Received 12 October 2017

Received in revised form 18 January 2018

Accepted 15 February 2018

Available online 24 February 2018

\section{Keywords:}

Monte Carlo particle modelling

Diffusion approach

Aerosols

Nucleation

Evaporation

Size distribution

\begin{abstract}
A B S T R A C T
The nucleation of sulphuric acid molecules plays a key role in the formation of aerosols. We here present a three dimensional particle Monte Carlo model to study the growth of sulphuric acid clusters as well as its dependence on the ambient temperature and the initial particle density. We initiate a swarm of sulphuric acid-water clusters with a size of $0.329 \mathrm{~nm}$ with densities between $10^{7}$ and $10^{8} \mathrm{~cm}^{-3}$ at temperatures between 200 and $300 \mathrm{~K}$ and a relative humidity of $50 \%$. After every time step, we update the position of particles as a function of size-dependent diffusion coefficients. If two particles encounter, we merge them and add their volumes and masses. Inversely, we check after every time step whether a polymer evaporates liberating a molecule. We present the spatial distribution as well as the size distribution calculated from individual clusters. We also calculate the nucleation rate of clusters with a radius of $0.85 \mathrm{~nm}$ as a function of time, initial particle density and temperature. The nucleation rates obtained from the presented model agree well with experimentally obtained values and those of a numerical model which serves as a benchmark of our code. In contrast to previous nucleation models, we here present for the first time a code capable of tracing individual particles and thus of capturing the physics related to the discrete nature of particles.
\end{abstract}

(C) 2018 The Author(s). Published by Elsevier Inc. This is an open access article under the CC BY license (http://creativecommons.org/licenses/by/4.0/).

\section{Introduction}

Nucleation of aerosols is the fundamental process by which gas condenses to form stable clusters. These clusters can potentially grow all the way to sizes where they can serve as cloud condensation nuclei (CCN), typically 50-100 nm. The nucleation phenomenon has been observed all around the globe [23] and is also considered to contribute to the formation of clouds on brown dwarfs and exoplanets [12,25]. About half of all CCN are estimated to originate from nucleated aerosols [29], making nucleation a relevant topic not only for aerosol research but also for its implications for cloud formation. Additionally both aerosols and clouds are relevant for e.g. climate change due to their large forcing effects [3]. The key molecule for aerosol nucleation has long been thought to be sulphuric acid (with water or other stabilizing molecules) due to its ability to form strong bonds [5]. Recently it has been shown that highly oxygenated organic molecules are also able to nucleate at high altitudes [2].

Traditionally nucleation has been described by classical thermodynamic nucleation theory [11], kinetic numerical models [32,27,39], or parametrisations based on either nucleation theory (e.g., [37]) or experimental data (e.g., [7]). The parametrisations and numerical models have the advantage that they can be adapted for use in global modelling [35,41,31] due to being computationally quick. Kazil and Lovejoy [17] used a semi-analytical approach to add aerosols to a global model.

\footnotetext{
* Corresponding author.

E-mail address: koehn@space.dtu.dk (C. Köhn).
} 
More recently an Atmospheric Cluster Dynamics Code (ACDC) has been developed solving the so-called birth-death equations, ordinary differential equations (ODEs) describing the temporal evolution of cluster densities of a given size [28]. The novelty of such a model is the automatic generation of ODEs for a given cluster size and its implementation into the solver whenever needed. This approach aims to reduce typographical errors when implementing ODEs manually. Such traditional numerical models can provide information with regards to particle size distributions and may reflect the physics satisfactory using actual data for condensation and evaporation. The information provided by these models is, however, focused on developments in time and not in space. If each molecule could be tracked in a three dimensional space it might be possible to achieve new insights into the process of nucleation.

Tracing individual particles in space and time is the main advantage of particle Monte Carlo codes. They are for example widely used to simulate the properties of lightning discharges $[4,19,20]$ by tracing individual electrons and photons or to study the nanostructure growth of atoms on surfaces in electrochemical models [14,15,9]. Recently, molecular dynamic models have also been used to study vapour-to-liquid nucleation [6] or homogeneous water nucleation [1].

Monte Carlo models give the opportunity to include all relevant microphysical processes as well as the interaction amongst all involved particles. In contrast to kinetic models or pure parametrisations which are based on averaged quantities, such as the density or concentration of particles or the mean energy, these models are able to capture rare events initiated by single particles $[33,13]$ as for example the production of gamma rays or positrons in the vicinity of lightning discharges [18].

The disadvantage of Monte Carlo codes is their runtime. Depending on the size of the problem Monte Carlo simulations can take up to several weeks whereas models based on averaged quantities take several hours to days [26]. For small systems, however, the time difference is not significant and Monte Carlo models offer a much better approach to the discrete nature of particles.

We here present a particle Monte Carlo code to study the nucleation of sulphuric acid clusters in 3D, which to our knowledge has not been done before. We here emphasize, however, that we not only present a new model to simulate the nucleation of sulphuric acid clusters, but also that the implemented physics is sufficient enough to study the nucleation of neutral sulphuric acid clusters in order to benchmark our model. Previously Monte Carlo studies have been used on the sulphuric-acid water system to study cluster parameters such as cluster shape, conformation and dissociation [22] as well as cluster free energies [16]. The paper is organized as follows. In section 2 we introduce the Monte Carlo particle model for the study of nucleation processes and discuss all the ingredients of this model: the implementation of single particles, diffusion coefficients, the collision of particles, the evaporation coefficients as well as the choice of the time step. In section 3 we discuss the spatial and size distribution of single sulphuric acid clusters and compare nucleation rates calculated with the present model with values from literature. We finally conclude in section 4 .

\section{Modelling}

For the study of the growth of $\mathrm{H}_{2} \mathrm{SO}_{4}-\mathrm{H}_{2} \mathrm{O}$ clusters, we introduce a particle Monte Carlo code tracing individual $\mathrm{H}_{2} \mathrm{SO}_{4}-\mathrm{H}_{2} \mathrm{O}$ clusters. In order to benchmark this model, we perform simulations with initial sulphuric acid molecule densities of $n=10^{7} \mathrm{~cm}^{-3}$ and of $10^{8} \mathrm{~cm}^{-3}$ at $200 \mathrm{~K}$ and $300 \mathrm{~K}$ as well as of $n=2.5 \cdot 10^{7} \mathrm{~cm}^{-3}$ at $238 \mathrm{~K}$ with a relative humidity of approximately $50 \%$.

In the simulations we do not distinguish between molecules and clusters, we simply refer to them as particles. Each particle is described as a sphere characterized by its position $\mathbf{r}=(x, y, z)$ in Cartesian coordinates. The particle's radius $R$ consisting of $k$ sulphuric acid molecules is determined through [38]

$$
R(k)=\sqrt[3]{\frac{3 m(k)}{4 \pi \varrho(k, T)}}
$$

implicitly including water content for a relative humidity of approx. 50\%. The mass and the density are given through [37]

$$
\begin{aligned}
m(k) & =\frac{0.098 \frac{\mathrm{kg}}{\mathrm{mol}}}{N_{A}} \cdot k+\frac{0.018 \frac{\mathrm{kg}}{\mathrm{mol}}}{N_{A}} \cdot \frac{k-k \cdot \mathcal{M} \mathcal{F}(k)}{\mathcal{M} \mathcal{F}(k)} \\
\varrho(k, T)\left[\frac{\mathrm{kg}}{\mathrm{cm}^{3}}\right]= & {\left[0.7681724+2.184714 \cdot \mathcal{M F}(k)+7.163002 \cdot \mathcal{M F}(k)^{2}\right.} \\
& -44.31447 \cdot \mathcal{M} \mathcal{F}(k)^{3}+88.75606 \cdot \mathcal{M F}(k)^{4} \\
& -75.73729 \cdot \mathcal{M} \mathcal{F}(k)^{5}+23.43228 \cdot \mathcal{M} \mathcal{F}(k)^{6}+T[\mathrm{~K}] \cdot(0.001808255-0.009294656 \cdot \mathcal{M F}(k) \\
& -0.03742147 \cdot \mathcal{M F}(k)^{2}+0.2565321 \cdot \mathcal{M F}(k)^{3}-0.5362872 \cdot \mathcal{M F}(k)^{4}+0.4857736 \cdot \mathcal{M F}(k)^{5} \\
& \left.-0.1629592 \cdot \mathcal{M} \mathcal{F}(k)^{6}\right)+T[\mathrm{~K}]^{2} \cdot(-0.000003478524+0.00001335867 \cdot \mathcal{M F}(k) \\
& +0.00005195706 \cdot \mathcal{M F}(k)^{2}-0.0003717636 \cdot \mathcal{M F}(k)^{3}+0.0007990811 \cdot \mathcal{M F}(k)^{4} \\
& \left.\left.-0.000745806 \cdot \mathcal{M F}(k)^{5}+0.000258139 \cdot \mathcal{M F}(k)^{6}\right)\right] \frac{1}{1000}
\end{aligned}
$$


with the Avogadro constant $N_{A} \approx 6.022 \cdot 10^{23} \mathrm{~mol}^{-1}$ and the mole fraction

$$
\mathcal{M F}(k)=0.4505 \cdot k^{-0.2097}
$$

which is a powerlaw fit to Fig. $2 \mathrm{~b}$ of [38] for a temperature of approx. $300 \mathrm{~K}$ for a humidity of $50 \%$. According to the same figure, we multiply (4) with a factor of $\approx 0.8$ for temperatures of $200 \mathrm{~K}$ and $238 \mathrm{~K}$.

After every time step $\Delta t$, the position is updated through

$$
\mathbf{r}(t+\Delta t)=\mathbf{r}(t)+\sqrt{2 D(R) \Delta t} \mathbf{G}
$$

where $\mathbf{G}=(\varrho \cos \phi \sin \theta, \varrho \sin \phi \sin \theta, \varrho \cos \theta)$ is a Gaussian random number [9] with $\varrho=\sqrt{-2 \log \left(r_{1}\right)}, \phi=2 \pi r_{2}, \theta=$ $\arccos \left(2 r_{3}-1\right), r_{i} \in[0,1) . D(R)=D_{0} \cdot(R(1) / R)^{2}$ depends on the particle size $R$ and on the diffusion coefficient [8]

$$
D_{0}=\frac{2}{3} \sqrt{\frac{k_{B}^{3} T^{3}}{\pi^{3} m(1)}} \frac{1}{4 P R(1)^{2}}
$$

for molecules where $R(1)=0.329 \mathrm{~nm}[21]$ and $m(1)=2.0033 \cdot 10^{-25} \mathrm{~kg}$ are the initial size and the mass of single sulphuric acid molecules without any attached water molecules. $k_{B} \approx 1.38 \cdot 10^{-23} \mathrm{~J} / \mathrm{K}$ is the Boltzmann constant and $P=1$ bar the ambient pressure. For $T=300 \mathrm{~K}, T=238 \mathrm{~K}$ and $T=200 \mathrm{~K}$ the diffusion coefficients are $D_{0} \approx 1.65 \cdot 10^{-6} \mathrm{~m}^{2} / \mathrm{s}, D_{0} \approx$ $1.16 \cdot 10^{-6} \mathrm{~m}^{2} / \mathrm{s}$ and $D_{0} \approx 8.96 \cdot 10^{-7} \mathrm{~m}^{2} / \mathrm{s}$.

The time step used is related to the time it takes a particle to diffuse the average separation between particles. The average separation between particles is $\sqrt[3]{1 / n}$ and the related diffusion length is $\sqrt{2 D_{0} \Delta t}$. Equating the two gives

$$
\Delta t \sim \frac{1}{2 D_{0} \sqrt[3]{n^{2}}}
$$

Hence it is $\Delta t \sim 0.653 \mathrm{~ms}$ for $n=10^{7} \mathrm{~cm}^{-3}$ and $300 \mathrm{~K}, \Delta t \sim 0.504 \mathrm{~ms}$ for $n=2.5 \cdot 10^{7} \mathrm{~cm}^{-3}$ and $238 \mathrm{~K}, \Delta t \sim 1.202 \mathrm{~ms}$ for $n=10^{7} \mathrm{~cm}^{-3}$ and $200 \mathrm{~K}$ as well as $\Delta t \sim 0.141 \mathrm{~ms}$ for $n=10^{8} \mathrm{~cm}^{-3}$ and $300 \mathrm{~K}$. Note that the actual time step should be $\lesssim \Delta t$ and that $\Delta t$ limits the maximal distance which a particle travels. Hence, we have chosen $\Delta t=100 \mu \mathrm{s}$ for $n=$ $10^{7} \mathrm{~cm}^{-3}$ and $300 \mathrm{~K}, \Delta t=250 \mu$ s for $n=2.5 \cdot 10^{7} \mathrm{~cm}^{7}$ and $238 \mathrm{~K}$ and $\Delta t=1 \mathrm{~ms}$ for $n=10^{7} \mathrm{~cm}^{7}$ and $200 \mathrm{~K}$. However, since the diffusion term in (5) depends on a Gaussian random number and since for polymers it is $D(R)<D_{0}$, the actual travelled distance is smaller than the maximally possible value. With $\Delta t=0.1 \mathrm{~ms}$ or $\Delta t=1 \mathrm{~ms}$, it is $\sqrt{2 D_{0} \Delta t} \approx 18 \mu \mathrm{m}$ for $300 \mathrm{~K}$ and $\sqrt{2 D_{0} \Delta t} \approx 42 \mu \mathrm{m}$ for $200 \mathrm{~K}$. Since the mean free path of sulphuric acid molecules in air is approximately 10-60 nm [34], hence significantly smaller than $1 \mu \mathrm{m}$, the justification of the diffusion approach in this study is justified.

After every time step we check whether two particles $i$ and $j$ with sizes $R_{i}$ and $R_{j}$ overlap by evaluating the condition

$$
\left|\mathbf{r}_{i}-\mathbf{r}_{j}\right| \leq R_{i}+R_{j}
$$

where $\mathbf{r}_{i}$ are $\mathbf{r}_{j}$ are the particles' positions. If this condition is fulfilled, the two particles are merged with new mass and radius according to (1) and (2); the new position is determined through

$$
\mathbf{r}_{i+j}=\frac{m_{i} \mathbf{r}_{i}+m_{j} \mathbf{r}_{j}}{m_{i}+m_{j}}
$$

Note that we add a new $\mathrm{H}_{2} \mathrm{SO}_{4}-\mathrm{H}_{2} \mathrm{O}$ cluster to the simulation domain at a random position after merging two particles if the particle number becomes smaller than the initial particle number; thus, the density of particles does not drop below the initial particle density.

Vice versa we also check after every time step whether a cluster with radius $R$ and mass $m$ evaporates by emitting one sulphuric acid molecule added to the simulation domain leaving a cluster with reduced mass and volume behind. For that purpose, we check after every time step and for every cluster whether

$$
r \leq P_{\text {eva }}
$$

for a random number $r \in[0,1)$ and for the evaporation probability $P_{\text {eva }}=1-\exp (-\gamma \Delta t)$. Here the evaporation frequency $\gamma$ for $300 \mathrm{~K}$ is adopted from [38]

$$
\gamma=\sqrt{\frac{8 \pi k_{B} T(m(1)+m(k))}{m(1) m(k)}}(R(1)+R(k))^{2} n_{a, s o l}^{\infty}(k, T) \exp \left(\frac{2 M_{1} \sigma(k, T)}{\varrho(k, T) \cdot \mathcal{R} \cdot T R(k, T)}\right)
$$

where the concentration $n_{a, s o l}^{\infty}$ of $\mathrm{H}_{2} \mathrm{SO}_{4}$ vapour molecules in the equilibrium vapour above a flat source and the surface tension are determined through $[30,37]$ 


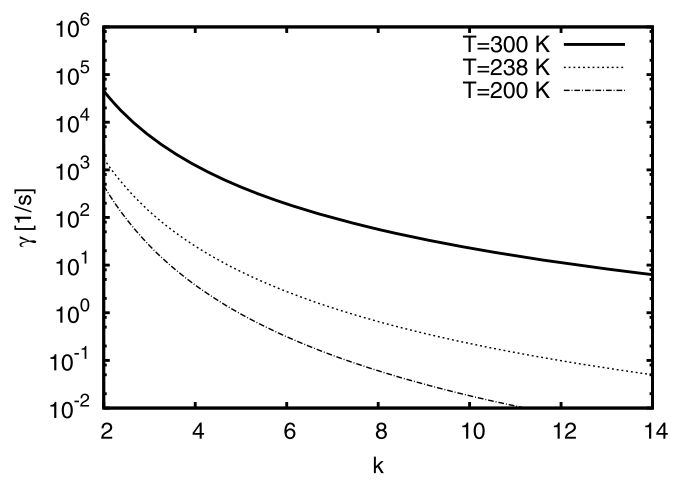

Fig. 1. The evaporation coefficient $\gamma$ (11) for temperatures of $200 \mathrm{~K}, 238 \mathrm{~K}$ and $300 \mathrm{~K}$ as a function of the number $k$ of sulphuric acid atoms in the cluster.

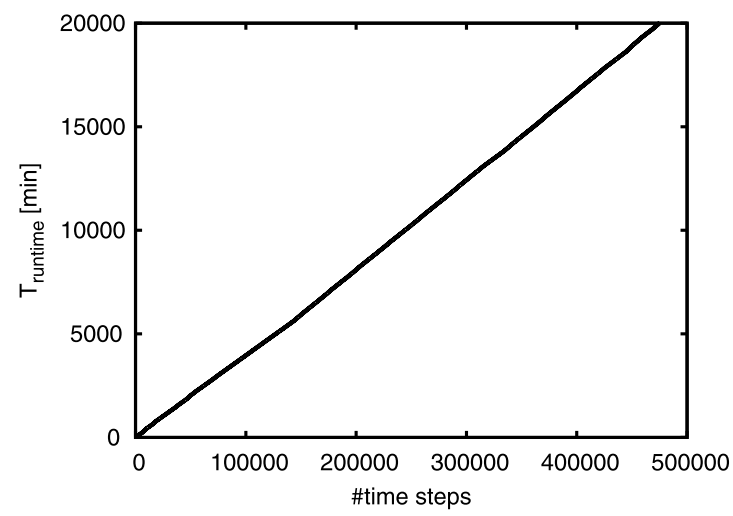

Fig. 2. The runtime of simulations as a function of time steps.

$$
\begin{aligned}
n_{a, s o l}^{\infty}(k, T)\left[\mathrm{m}^{-3}\right] & =0.0017241 \cdot \mathcal{M F}(k)^{10.891} \cdot \frac{133}{T[\mathrm{~K}] \cdot \mathcal{R}} \cdot N_{A} \\
\sigma\left[\mathrm{N} \mathrm{m}^{-1}\right] & =0.11864-0.11651 \cdot \mathcal{M F}(k)+0.76852 \cdot \mathcal{M F}(k)^{2}-2.40909 \cdot \mathcal{M F}(k)^{3}+2.95434 \cdot \mathcal{M F}(k)^{4} \\
& -1.25852 \cdot \mathcal{M F}(k)^{5}+T[\mathrm{~K}] \cdot\left(-0.00015709+0.00040105 \cdot \mathcal{M F}(k)-0.0023995 \cdot \mathcal{M F}(k)^{2}\right. \\
& \left.+0.007611235 \cdot \mathcal{M F}(k)^{3}-0.00937386 \cdot \mathcal{M F}(k)^{4}+0.00389722 \cdot \mathcal{M F}(k)^{5}\right)
\end{aligned}
$$

$M_{1}=98 \mathrm{~g} \mathrm{~mol}^{-1}$ is the molar mass of $\mathrm{H}_{2} \mathrm{SO}_{4}$ [24, pp. 1661-1665] and $\mathcal{R} \approx 8.31 \mathrm{~J}$ (mol K) ${ }^{-1}$ the universal gas constant. Because of the lack of physical data, e.g. for the equilibrium vapour pressure, we multiply Eq. (11) with a factor of $\approx 10^{-4}$ for $238 \mathrm{~K}$ and of $\approx 10^{-5}$ for $200 \mathrm{~K}$ based on Fig. 4 of [38]. For better accuracy, we use Eq. (11) for $k>5$ only; for $k \leq 5$, we use distinct values extracted from [38]. Fig. 1 shows the evaporation coefficient $\gamma$ as a function of $\mathrm{k}$ for $200 \mathrm{~K}, 238 \mathrm{~K}$ and $300 \mathrm{~K}$. For all considered cases evaporation is most efficient for small cluster sizes and becomes less probable with increasing size. For $200 \mathrm{~K}$ and $238 \mathrm{~K} \gamma$ is several orders of magnitude smaller than for $300 \mathrm{~K}$, thus compared to $300 \mathrm{~K}$ evaporation is much less likely and nearly negligible for $200 \mathrm{~K}$. Since the emitted molecule is added to the simulation domain, the particle density slightly increases; however, we have observed that it does not exceed $1.002 \cdot 10^{7} \mathrm{~cm}^{-3}$ for an initial density of $10^{7} \mathrm{~cm}^{-3}$ and $1.009 \cdot 10^{8} \mathrm{~cm}^{-3}$ for an initial density of $10^{8} \mathrm{~cm}^{-3}$.

In order to optimize the runtime of our simulations, we have chosen the volume of the simulation domain to be $10^{-4} \mathrm{~cm}^{3}$ for a density of $10^{7} \mathrm{~cm}^{-3}, 4 \cdot 10^{-5} \mathrm{~cm}^{3}$ for a density of $2.5 \cdot 10^{7} \mathrm{~cm}^{-3}$, and $10^{-5} \mathrm{~cm}^{3}$ for a density of $10^{8} \mathrm{~cm}^{-3}$. Consequently we initiate all simulations by placing 1000 individual $\mathrm{H}_{2} \mathrm{SO}_{4}$ molecules at random positions into the simulation domain which scales with the concentration.

\section{Results}

In the following we discuss the spatial distribution and the size distribution of all particles as well as the nucleation rates of clusters with a radius of $0.85 \mathrm{~nm}$. As supplementary material we have added movies showing the temporal evolution of the particle position and size for $n=10^{7} \mathrm{~cm}^{-3}$ and $200 \mathrm{~K}$ as well as for $n=10^{7} \mathrm{~cm}^{-3}$ and $300 \mathrm{~K}$.

Fig. 2 shows the runtime of all simulations as a function of time steps. The runtime increases linearly because of the approximate constancy of the number of simulated particles. In all considered cases it takes approximately $10^{4}$ minutes 


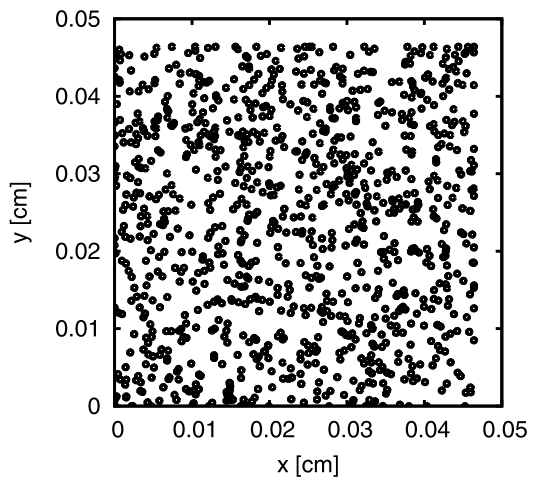

a) $n=10^{7} \mathrm{~cm}^{-3}, T=300 \mathrm{~K}, t=50 \mathrm{~s}$

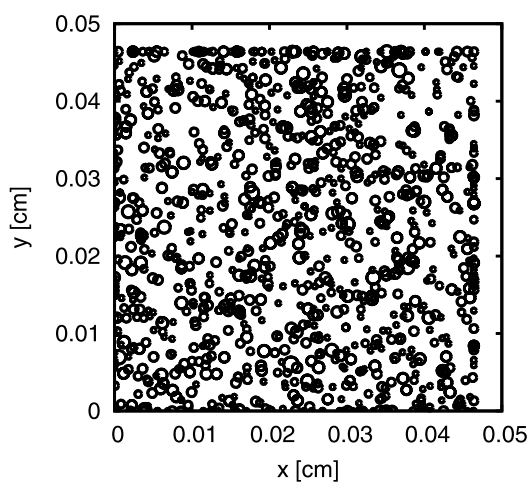

c) $n=10^{7} \mathrm{~cm}^{-3}, T=200 \mathrm{~K}, t=50 \mathrm{~s}$

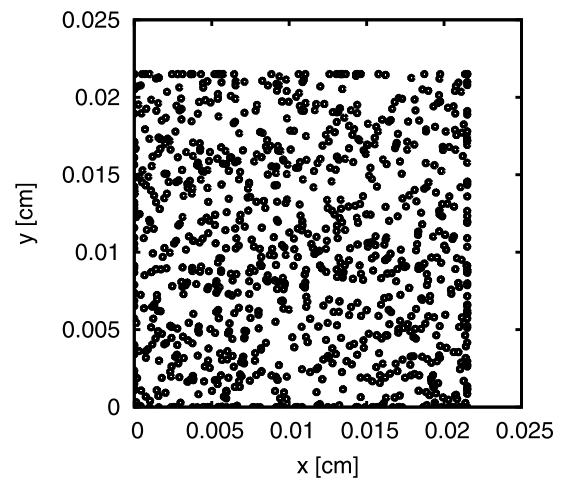

b) $n=10^{8} \mathrm{~cm}^{-3}, T=300 \mathrm{~K}, t=50 \mathrm{~s}$

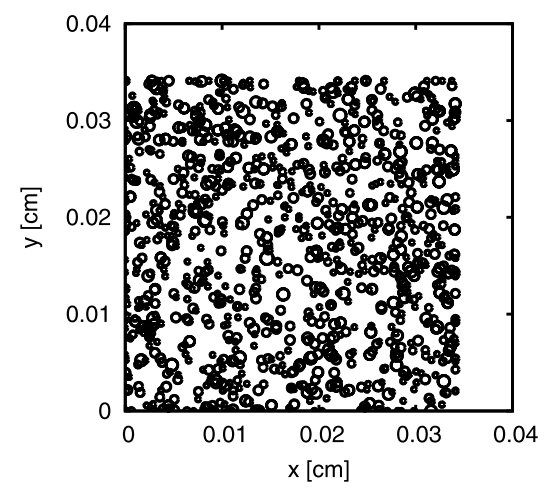

d) $n=2.5 \cdot 10^{7} \mathrm{~cm}^{-3}, T=238 \mathrm{~K}, t=50 \mathrm{~s}$

Fig. 3. The spatial distribution of all particles after $50 \mathrm{~s}$ for different densities and different temperatures projected onto the $x y$ plane. For better visibility the size of each circle is the real size of each particle multiplied by a factor of $10^{6}$.

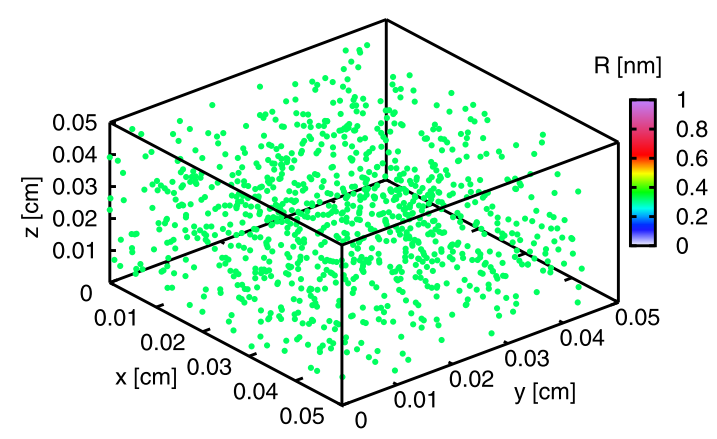

a) $n=10^{7} \mathrm{~cm}^{-3}, T=300 \mathrm{~K}$

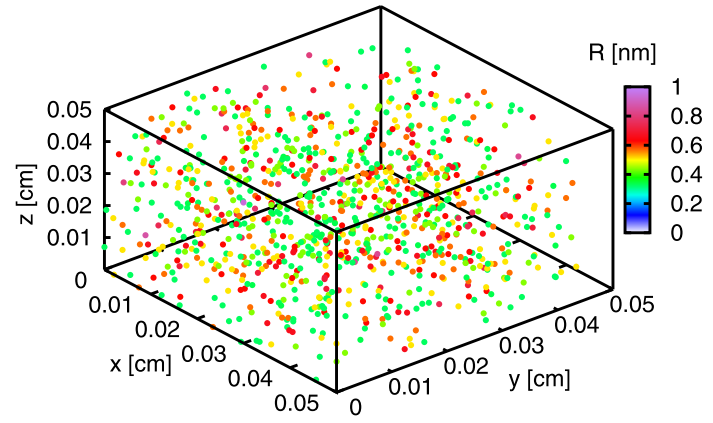

b) $n=10^{7} \mathrm{~cm}^{-3}, T=200 \mathrm{~K}$

Fig. 4. The position of all particles in the three dimensional simulation domain after $50 \mathrm{~s}$ for the same densities and temperatures as in Fig. 3 a) and d). The particle size is colour coded. (For interpretation of the colours in the figure(s), the reader is referred to the web version of this article.)

or equivalently 7 days per 250000 time steps which can easily be translated into physical time knowing the size of the computational time step.

\subsection{Spatial distribution}

Fig. 3 shows the spatial distribution of all particles projected onto the $x y$ plane after 50 s. For better visibility we have multiplied the real size of each particle by a factor of $10^{6}$. Fig. 4 illustrates the capability of the present model for full three dimensional simulations. It shows the spatial distribution after the same time steps and for the same densities and temperatures as in Fig. 3 a) and c). Fig. 3 and 4 demonstrate that in all cases the particles are distributed randomly within the simulation domain. Panels a) and b) of Fig. 3 show that for $T=300 \mathrm{~K}$, there is no growth at all; the average radius of all particles after $50 \mathrm{~s}$ is approximately $0.329 \mathrm{~nm}$. In contrast to a temperature of $300 \mathrm{~K}$ where the simulation is evaporation 


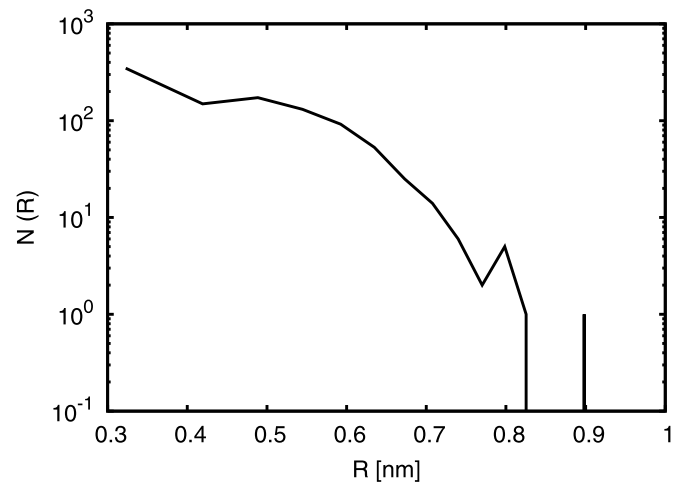

a) $n=10^{7} \mathrm{~cm}^{-3}, T=200 \mathrm{~K}, t=50 \mathrm{~s}$

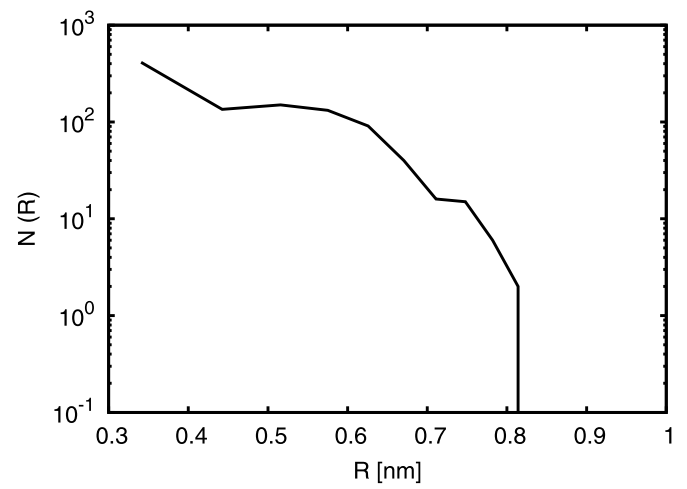

c) $n=2.5 \cdot 10^{7} \mathrm{~cm}^{-3}, T=238 \mathrm{~K}, t=50 \mathrm{~s}$

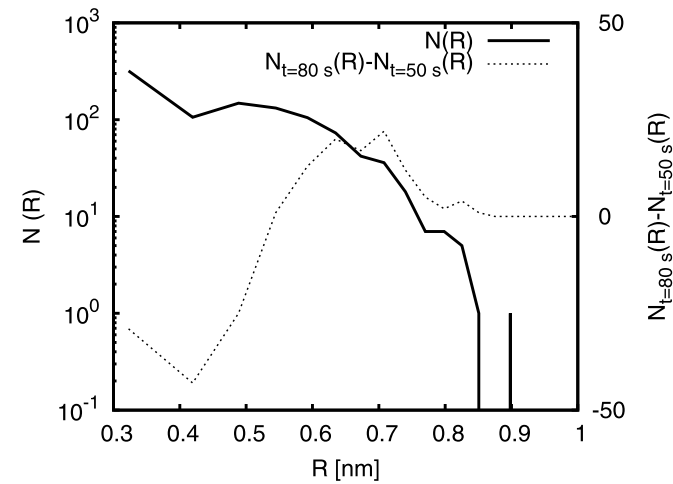

b) $n=10^{7} \mathrm{~cm}^{-3}, T=200 \mathrm{~K}, t=80 \mathrm{~s}$

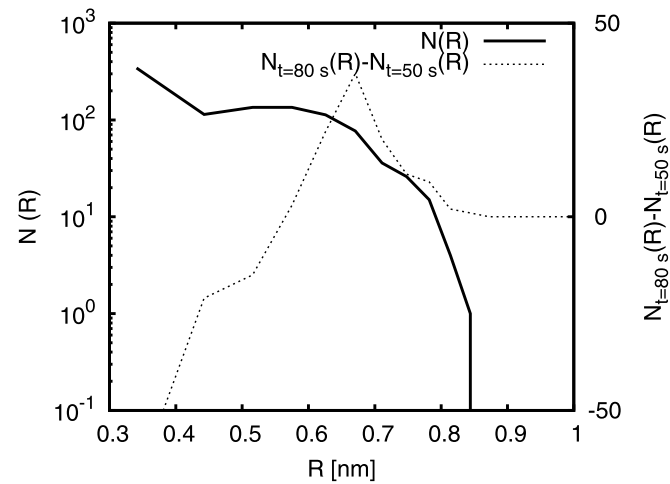

d) $n=2.5 \cdot 10^{7} \mathrm{~cm}^{-3}, T=238 \mathrm{~K}, t=80 \mathrm{~s}$

Fig. 5. The size distribution of all particles after $50 \mathrm{~s}$ (left column) and after $80 \mathrm{~s}$ (right column) for the same conditions as in Fig. $3 \mathrm{c}$ ) and d). The right $y$-axis in the right column shows the difference between the particle numbers after $80 \mathrm{~s}$ and after $50 \mathrm{~s}$.

dominated, there is a significant growth of clusters for a temperature of $200 \mathrm{~K}$ and $238 \mathrm{~K}$ where evaporation is less probable to negligible. The average size is $0.48 \mathrm{~nm}$ for $200 \mathrm{~K}$ and $0.46 \mathrm{~nm}$ for $238 \mathrm{~K}$.

\subsection{Size distribution}

Fig. 5 shows the size distributions after $50 \mathrm{~s}$ and after $80 \mathrm{~s}$ for $200 \mathrm{~K}$ and $238 \mathrm{~K}$. The right $y$-axis in the right column displays the difference between the particle numbers after $80 \mathrm{~s}$ and after $50 \mathrm{~s}$.

For all considered cases, the number of monomers with a size of $0.329 \mathrm{~nm}$ is dominant after $50 \mathrm{~s}$ whilst there are only a few clusters with larger sizes. For $T=300 \mathrm{~K}$, there are no particles larger than $0.329 \mathrm{~nm}$; for $T=238 \mathrm{~K}$ (c) and $200 \mathrm{~K}$ (a), approximately half of all particles are larger than $0.329 \mathrm{~nm}$. For $200 \mathrm{~K}$ and $238 \mathrm{~K}$, the large number of polymers is an effect of the improbable or negligible evaporation.

After $80 \mathrm{~s}$, the size distributions at $300 \mathrm{~K}$ have not changed at all. Panel a, however, shows that for a temperature of $200 \mathrm{~K}$, the number of monomers has decreased enormously since there is only nucleation, but no evaporation. The right $y$-axis of panels b) and d) show that there is an increase of polymers with sizes above $0.8 \mathrm{~nm}$; this effect is more significant for $200 \mathrm{~K}$ than for $238 \mathrm{~K}$ since evaporation is more likely for the latter case.

\subsection{Nucleation rate}

For $300 \mathrm{~K}$, the simulation is evaporation dominated. Hence we do not observe any polymers and conclude that the nucleation rate is 0.0 . In the case of $238 \mathrm{~K}$ and $200 \mathrm{~K}$, there is an interplay between the nucleation through the approach of particles and the evaporation. As Fig. 3 and 5 show, there is a significant growth of the particle sizes. After every time step $t$ we therefore count the number $N(R, t)$ of particles with size $R$. Subsequently the nucleation rate of particles with size $R$ as a function of time $t$ is given through

$$
v(R, t)=\frac{N(R, t)}{V \cdot t}
$$

where $V$ is the volume of the simulation domain. 


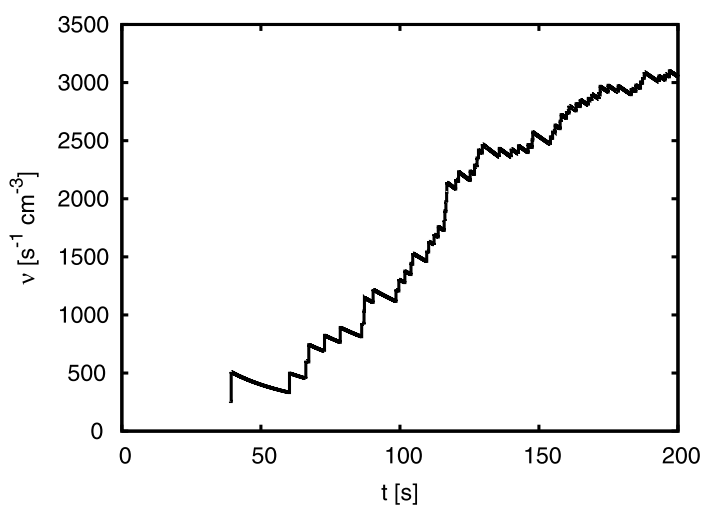

Fig. 6. The nucleation rate $v(t)$ as a function of time for $n_{0}=10^{7} \mathrm{~cm}^{-3}$ for $200 \mathrm{~K}$.

Table 1

The nucleation rates $v_{\text {sim }}$ calculated from our simulations, the nucleation rates $v_{\text {par }}$ [7] and the nucleation rates by [43].

\begin{tabular}{llll}
\hline & $v_{\text {sim }}\left[\mathrm{cm}^{-3} \mathrm{~s}^{-1}\right]$ & $v_{\text {par }}\left[\mathrm{cm}^{-3} \mathrm{~s}^{-1}\right]$ & $v_{y u}\left[\mathrm{~cm}^{-3} \mathrm{~s}^{-1}\right]$ \\
\hline$n=10^{7} \mathrm{~cm}^{-3}, T=300 \mathrm{~K}$ & 0.0 & $10^{-8.19}$ & $10^{-46.92}$ \\
$n=10^{7} \mathrm{~cm}^{-3}, T=200 \mathrm{~K}$ & $\approx 10^{3.42 \pm 1.77}$ & $10^{2.45}$ & $10^{3.11}$ \\
$n=10^{8} \mathrm{~cm}^{-3}, T=300 \mathrm{~K}$ & 0.0 & $10^{-4.57}$ & $10^{-35.40}$ \\
$n=2.5 \cdot 10^{7} \mathrm{~cm}^{-3}, T=238 \mathrm{~K}$ & $10^{2.05 \pm 2.38}$ & $10^{-0.16}$ & $10^{0.04}$ \\
\hline
\end{tabular}

As an example, Fig. 6 shows the nucleation rate $v(R=0.85 \mathrm{~nm}, t)$ of particles with a radius of $0.85 \mathrm{~nm}$ as a function of time for $n=10^{7} \mathrm{~cm}^{-3}$ and $T=200 \mathrm{~K}$. For comparison with literature, e.g. with [7], we have chosen a radius of 0.85 $\mathrm{nm}$; however, this critical size is rather arbitrary. One of the advantages of the introduced model here is the possibility to determine the nucleation rate of particles of any size. For $200 \mathrm{~K}$, evaporation is negligible and thus particles keep growing and consequently the nucleation rate increases as a function of time. In the beginning, the nucleation rate grows slowly since it takes time for the first clusters to reach the nucleation size. However, the slope of the nucleation rate flattens because of the decreased diffusion coefficient for larger clusters which diffuse more slowly than small clusters and single molecules and consequently collide less with surrounding particles.

We here define the mean nucleation rate of particles with a radius of $0.85 \mathrm{~nm}$ and above within time interval $\mathcal{T}$ as

$$
v_{\text {sim }}=\langle v\rangle=\frac{1}{\mathcal{T}} \sum_{t} v(R \geq 0.85 \mathrm{~nm}, t) .
$$

Dunne et al. [7] simulated the formation of atmospheric aerosol particles in extensive laboratory experiments. They determined the nucleation rates for aerosols at different temperatures and for different compounds and derived the parametrisation

$$
v_{\text {par }}\left(n\left[10^{6} / \mathrm{cm}^{3}\right], T[K]\right)=n\left[10^{6} / \mathrm{cm}^{3}\right]^{3.62} \cdot e^{46.3-\frac{245.0 T[K]}{1000.0}}
$$

for the neutral nucleation rate of sulphuric acid-water clusters with a radius of $0.85 \mathrm{~nm}$ as a function of the density $\mathrm{n}$ in units of $10^{6}$ molecules $/ \mathrm{cm}^{3}$ and of the temperature $\mathrm{T}$ in Kelvin. Additionally, Yu [43] set up a website which calculates nucleation rates $v_{y u}$ based on [40] and [42].

Table 1 compares the nucleation rates $v_{\text {sim }}$ calculated from our simulations with the nucleation rates $v_{p a r} v_{y u}$. In all cases $v_{\text {sim }}$ is comparable to the values obtained by Dunne et al. [7] or [43], hence there is a good agreement within the error bars. This might be due to underestimating the evaporation coefficient. However, from the available data, it is difficult to get the exact values for the evaporation coefficients. However, we here emphasize that this paper is not about finding the best input data, but to introduce a code that - provided sufficiently accurate input data - models nucleation on a particle level.

\section{Conclusions}

We have presented a particle Monte Carlo model tracing individual $\mathrm{H}_{2} \mathrm{SO}_{4}-\mathrm{H}_{2} \mathrm{O}$ clusters for different initial densities, $n$, of sulphuric acid molecules and for different temperatures $T$ taking the growth by collision of particles and evaporation by single $\mathrm{H}_{2} \mathrm{SO}_{4}$ molecules into account.

Four cases were considered, $n=10^{7} \mathrm{~cm}^{-3}$ with temperature either $T=300 \mathrm{~K}$ or $T=200 \mathrm{~K}$, one case with $n=2.5$. $10^{7} \mathrm{~cm}^{-3}$ and $T=238 \mathrm{~K}$ and one case with $n=10^{8} \mathrm{~cm}^{-3}$ and $T=300 \mathrm{~K}$. In the two cases at $300 \mathrm{~K}$, there is no significant 
growth between $50 \mathrm{~s}$ and $80 \mathrm{~s}$, in accordance with a low nucleation rate. However, for $200 \mathrm{~K}$ and $238 \mathrm{~K}$, growth of clusters between $50 \mathrm{~s}$ and $80 \mathrm{~s}$ is observed.

The simulations make it possible to calculate the size distribution based on individual particle sizes. For $300 \mathrm{~K}$, all particles are single molecules. This behaviour is rather independent of the initial density. In contrast at $200 \mathrm{~K}$ and $238 \mathrm{~K}$, evaporation becomes improbable or negligible and thus the size distribution consists of fewer monomers compared to the case with $T=300 \mathrm{~K}$ which increases the number of clusters above $0.329 \mathrm{~nm}$.

Finally we have calculated the nucleation rates as a function of time and the mean nucleation rates averaged over time. Since for $300 \mathrm{~K}$ there is an interplay between nucleation and evaporation, the nucleation rate is 0 . For lower temperatures, evaporation is less likely and as such the nucleation rate increases with time. However, it tends to an upper limit since the probability of two particles colliding with each other is reduced as an effect of the decreased diffusion coefficient.

We compared the nucleation rates with values experimentally obtained by Dunne et al. [7] and F. Yu [43]. Within the given error bars we see a good agreement between our simulation results and experimental values which serves as a benchmark for our Monte Carlo code. We therefore conclude that the physics implemented in the present Monte Carlo model is appropriate to simulate the growth of sulphuric acid clusters. Its main advantage is that it traces individual particles and therefore reflects their distinct nature and as such reality much better than for example kinetic numerical models or pure parametrisations.

Subsequently, the 3D particle approach allows us to study new phenomena. In future work, we intend to investigate how the temporal evolution of the nucleation rate changes for fixed particle densities and different volumes, thus different particle numbers. Such a task is ideal for a model tracing individual particles and cannot be studied with kinetic numerical models or pure parametrisations.

The model presented in this paper can easily be adjusted to study nucleation phenomena of other species in different temperatures and pressures. Lee et al. [25] studied the formation of $\mathrm{TiO}_{2}$ and $\mathrm{SiO}$ clusters on brown dwarfs and extra-solar planets. They use a classical nucleation theory where they allow only monomers to attach to other monomers or clusters. In future work, we will adjust our model to include cluster-cluster collisions and to study their effects on the nucleation of clusters in the atmospheres of exoplanets.

In a forthcoming paper, we will finally present a more sophisticated model where we include $\mathrm{HSO}_{4}^{-}$ions and investigate their influence on the nucleation rate. Not only is this of relevance for aerosol formation [10] and growth [36] in Earth's atmosphere, but this model can be adjusted to study the influence of ions in exoplanets' atmospheres which has not been considered before.

\section{Acknowledgement}

The research was partly funded by the Marie Curie Actions of the European Union's Seventh Framework Programme (FP7/2007-2013) under REA grant agreement $\mathrm{n}^{0} 609405$ (COFUNDPostdocDTU).

\section{Appendix A. Supplementary material}

Supplementary material related to this article can be found online at https://doi.org/10.1016/j.jcp.2018.02.032.

\section{References}

[1] R. Angélil, J. Diemand, K.K. Tanaka, H. Tanaka, Homogeneous SPC/E water nucleation in large molecular dynamics simulations, J. Chem. Phys. 143 (2015) 064507.

[2] F. Bianchi, J. Trostl, H. Junninen, C. Frege, S. Henne, C.R. Hoyle, U. Molteni, E. Herrmann, A. Adamov, N. Bukowiecki, X. Chen, J. Duplissy, M. Gysel, M. Hutterli, J. Kangasluoma, J. Kontkanen, A. Kuerten, H.E. Manninen, S. Muench, O. Perakyla, T. Petaja, L. Rondo, C. Williamson, E. Weingartner, J. Curtius, D.R. Worsnop, M. Kulmala, J. Dommen, U. Baltensperger, New particle formation in the free troposphere: a question of chemistry and timing, Science 352 (2016) 1109-1112, https://doi.org/10.1126/science.aad5456.

[3] O. Boucher, D. Randall, P. Artaxo, C. Bretherton, G. Feingold, P. Forster, V.-M. Kerminen, Y. Kondo, H. Liao, U. Lohmann, P. Rasch, S. Satheesh, S. Sherwood, B. Stevens, X.Y. Zhang, Clouds and aerosols, in: Climate Change 2013: The Physical Science Basis. Contribution of Working Group I to the Fifth Assessment Report of the Intergovernmental Panel on Climate Change, Cambridge University Press, 2013.

[4] O. Chanrion, T. Neubert, A PIC-MCC code for simulations of streamer propagation in air, J. Comput. Phys. 227 (2008) $7222-7245$

[5] J. Curtius, Nucleation of atmospheric aerosol particles, C. R. Phys. 7 (2006) 1027-1045.

[6] J. Diemand, R. Angélil, K.K. Tanaka, H. Tanaka, Large scale molecular dynamics simulations of homogeneous nucleation, J. Chem. Phys. 139 (2013) 074309 .

[7] E.M. Dunne, et al., Global atmospheric particle formation from CERN CLOUD measurements, Science 354 (2016) 1119-1124.

[8] F. Durst, Grundlagen der Strömungsmechanik: Eine Einführung in die Theorie der Strömung von Fluiden, Springer, Berlin, 2006.

[9] J.L. Fransaer, R.M. Penner, Brownian dynamics simulation of the growth of metal nanocrystal ensembles on electrode surfaces from solution, I. Instantaneous nucleation and diffusion-controlled growth, J. Phys. Chem. B 103 (1999) 7643-7653.

[10] H. Gordon, et al., Causes and importance of new particle formation in the present-day and preindustrial atmospheres, J. Geophys. Res., Atmos. 122 (2017) 8739-8760.

[11] P. Hamill, R.P. Turco, C.S. Kiang, O.B. Toon, R.C. Whitten, An analysis of various nucleation mechanisms for sulfate particles in the stratosphere, J. Aerosol Sci. 13 (1982) 561-585.

[12] C. Helling, A. Fomins, Modelling the formation of atmospheric dust in brown dwarfs and planetary atmospheres, Philos. Trans. R. Soc. A 371 (2013) 20110581.

[13] M. Hsieh, Adaptive Monte Carlo methods for rare event simulations, in: Proceedings - Winter Simulation Conference, vol. 1, 2002, pp. 108-115. 
[14] P. Jensen, et al., Controlling nanostructures, Nature 368 (1994) 22.

[15] P. Jensen, et al., Deposition, diffusion and aggregation of atoms on surfaces: a model for nanostructure growth, Phys. Rev. B 50 (1994) 15316-15330.

[16] S.M. Kathmann, B.N. Hale, Monte Carlo simulations of small sulfuric acid-water clusters, J. Phys. Chem. B 105 (2001) $11719-11728$.

[17] J. Kazil, E.R. Lovejoy, A semi-analytical method for calculating rates of new sulfate aerosol formation from the gas phase, Atmos. Chem. Phys. 7 (2007) 3447-3459.

[18] C. Köhn, U. Ebert, Calculation of beams of positrons, neutrons and protons associated with terrestrial gamma-ray flashes, J. Geophys. Res. 120 (2015) $1620-1635$.

[19] C. Köhn, et al., Leptons, hadrons and photons and their feedback close to lightning leaders, J. Geophys. Res. 122 (2017) $1365-1383$.

[20] C. Köhn, et al., Electron acceleration during streamer collisions in air, Geophys. Res. Lett. 44 (2017) 2604-2613.

[21] R.L. Kuczkowski, et al., Microwave spectrum, structure, and dipole moment of sulfuric acid, J. Am. Chem. Soc. 1981 (1981) 2561-2566.

[22] I. Kusaka, et al., Binary nucleation of sulfuric acid-water: Monte Carlo simulation, J. Chem. Phys. 108 (1998) 6829-6848.

[23] M. Kulmala, H. Vehkamäki, T. Petäjä, M. Dal Maso, A. Lauri, V.M. Kerminin, W. Birmili, P.H. McMurry, Formation and growth rates of ultrafine atmospheric particles: a review of observations, J. Aerosol Sci. 35 (2004) 143-176.

[24] N.A. Lange, J.A. Dean, Lange's Handbook of Chemistry, McGraw-Hill, New York, 1967.

[25] G. Lee, et al., Dust in brown dwarfs and extra-solar planets IV. Assessing $\mathrm{TiO}_{2}$ and SiO nucleation for cloud formation modelling, Astron. Astrophys. 575 (2015) A11.

[26] C. Li, et al., A comparison of 3D particle, fluid and hybrid simulations for negative streamers, Plasma Sources Sci. Technol. 21 (2012) 055019.

[27] E.R. Lovejoy, J. Curtius, K.D. Froyd, Atmospheric ion-induced nucleation of sulphuric acid and water, J. Geophys. Res., Atmos. 109 (2004) 1-11, https:// doi.org/10.1029/2003JD004460.

[28] M.J. McGrath, et al., Atmospheric cluster dynamics code: a flexible method for solution of birth-death equations, Atmos. Chem. Phys. 12 (2012) 2345-2355.

[29] J. Merikanto, D.V. Spracklen, G.W. Mann, S.J. Pickering, K.S. Carslaw, Impact of nucleation on global CCN, Atmos. Chem. Phys. 9 (2009) 8601-8616.

[30] M. Noppel, H. Vehkamäki, M. Kulmala, An improved model for hydrate formation in sulfuric acid-water nucleation, J. Chem. Phys. 116 (2002) 218-228.

[31] J.R. Pierce, P.J. Adams, Uncertainty in global CCN concentrations from uncertain aerosol nucleation and primary emission rates, Atmos. Chem. Phys. 9 (2009) 1339-1356

[32] M. Pirjola, M. Kulmala, Modelling the formation H2SO4-H2O particles in rural, urban and marine conditions, Atmos. Res. 46 (1998) 321-347.

[33] G. Rubino, B. Tuffin, Rare Event Simulation Using Monte Carlo Methods, John Wiley \& Sons Ltd., West Sussex, 2009.

[34] J.H. Seinfeld, S.N. Pandis, Atmospheric Chemistry and Physics, John Wiley \& Sons, New Jersey, 2006.

[35] D.V. Spracklen, et al., The contribution of boundary layer nucleation events to total particle concentrations on regional and global scales, Atmos. Chem. Phys. 6 (2006) 5631-5648.

[36] H. Svensmark, M.B. Enghoff, N.J. Shaviv, J. Svensmark, Increased ionization supports growth of aerosols into cloud condensation nuclei, Nat. Commun. 8 (2017) 2199

[37] H. Vehkamaki, M. Kulmala, I. Napari, K. Lehtinen, C. Timmreck, M. Noppel, A. Laaksonen, An improved parameterization for sulfuric acid-water nucleation rates for tropospheric and stratospheric conditions, J. Geophys. Res., Atmos. 107 (2002), https://doi.org/10.1029/2002JD002184.

[38] F. Yu, Quasi-unary homogeneous nucleation of $\mathrm{H}_{2} \mathrm{SO}_{4}-\mathrm{H}_{2} \mathrm{O}$, J. Chem. Phys. 122 (2005) 074501.

[39] F. Yu, From molecular clusters to nanoparticles: second generation ion-mediated nucleation model, Atmos. Chem. Phys. 6 (2006) 5193-5211.

[40] F. Yu, Improved quasi-unary nucleation model for binary $\mathrm{H}_{2} \mathrm{SO}_{4}-\mathrm{H}_{2} \mathrm{O}$ homogeneous nucleation, J. Chem. Phys. 127 (2007) 054301.

[41] F. Yu, et al., Ion-mediated nucleation as an important global source of tropospheric aerosols, Atmos. Chem. Phys. 8 (2008) 2537-2554.

[42] F. Yu, Updated $\mathrm{H}_{2} \mathrm{SO}_{4}-\mathrm{H}_{2} \mathrm{O}$ binary homogeneous nucleation rate look-up tables, J. Geophys. Res. 113 (2008) D24201.

[43] F. Yu, http://www.albany.edu/ yfq/cgi/YuOnLineBHN.html. 